\title{
Experiential Aspects of Tourism Gift Consumption
}

\begin{abstract}
This paper addresses how consumers make use of fantasy, feelings, and fun when deciding, giving and consuming gifts of tourism and leisure. Despite little industry awareness, consumers are engaging with such behaviour because tourism gifts offer considerable scope for the creative expression of donor-recipient relationships. This UK-based interpretive qualitative study captured data from donors, recipients and tourism and leisure providers. The feelings (emotions), fantasies (imagination and dreaming) and fun (playfulness) were interrogated through the behavioural phases of gift decision making, gift exchange, postexchange and gift consumption. A range of emotions were displayed by donors and recipients and at different stages in the gift giving process; donor decision making in groups for created gifts was particularly charged. Fantasies were evident both for donors planning gifts and for recipients. As an intangible gift, means of exchange allowed for creative mechanisms beyond the classic wrapping strategies associated with physical gifts. The 'decoy' strategy stimulated the recipient's imagination to conjure fantastical scenarios. Fun or playfulness was built into many of the gifts and often related to an element of 'surprise', an attribute of the perfect gift (eg Belk, 1996) in Western societies.
\end{abstract}

\section{Keywords}

tourism gifts, hedonic gifts, experiential consumption

\section{Introduction}

The purpose of this paper is to examine the behaviour of consumers in the decision making, exchange, and consumption of gifts that are tourism and leisure products, with a particular focus on their experiences of feelings, fantasy and fun throughout the consumption process. In line with the gift giving literature, consumers who give tourism and leisure gifts to others are referred to as 'donors' and consumers who receive tourism and leisure gifts from others are referred to as 'recipients'. The paper addresses an important gap in the literature 
pertaining to tourism as gifts and, through proposing seven focal areas of practical relevance for tourism and leisure marketers, seeks to partially close the divide between academic theory and current industry practice. The research is concerned with the gift giving behaviours of individuals nurturing personal relationships and who use tourism and leisure products to this end. Topics such as corporate giving and philanthropic giving deal less with personal relationships between individuals and are outside the scope and nature of this research.

There are two well established bodies of literature that direct this paper, namely the extant literatures on hedonic and experiential consumption and on gift giving behaviour. Each embraces contributions from a variety of disciplines and research approaches. Whilst tourism and leisure is an acknowledged product category with intrinsic connections to hedonic and experiential consumption (Holbrook and Hirschman, 1982), such intangible and perishable products have been sparingly documented in the academic gift giving literature, despite the realities of consumers utilising tourism and leisure as gifts in their personal relationships. For the purpose of this paper, the literature on hedonic and experiential consumption offered the widest vantage point for conceptualisation, whilst the literature on gift giving behaviour provided the focus. Behind these two lies the solid body of literature on tourism and leisure, which sensitised the researcher to the topic and which was drawn down into the discussion as warranted.

\section{Hedonic and experiential consumption.}

With roots in postmodernist thinking (Parsons and Maclaren, 2009) and the 1980s mid-life crisis of marketing (Caru and Cova, 2003), it was the pioneering work by Hirschman and Holbrook (Hirschman and Holbrook, 1982; Holbrook and Hirschman, 1982) that drove the emergence of experiential consumption (Caru and Cova, 2003; Tynan and McKechnie, 2009a). With a carefully crafted argument for an alternative perspective on consumer behaviour to rational decision making and information processing, Hirschman and Holbrook made the case for re-balancing academic investment away from decision making alone and towards product usage - indeed, to the entirety of the consumption process through to recollection and memory (Tynan and McKechnie, 2009a). Holbrook and Hirschman (1982) encapsulated experiential consumption through the 'three F's' of fantasies (imagination and dreaming), feelings (emotions), and fun (pleasure and playfulness). Despite the proposal of other formulations, for example Holbrook's (2000: 178) 'four E's' of experience, 
entertainment, exhibitionism and evangelising, the original three F's offer an insightful structure for investigating tourism gift giving.

These early papers offered definitions of hedonic consumption as 'those facets of consumer behaviour that relate to the multisensory, fantasy and emotive aspects of product use' (Hirschman and Holbrook, 1982: 99-100). The term multisensory referred to the tastes, sounds, scents, tactile impressions and visual imagery perceived by an individual, and recognised the impressions both as inputs ('afferent') and as generated by the individual in reaction to these inputs ('efferent') ie mutually evocative. This latter internal imagery included 'historic imagery' with the recollection of an actual event in the individual's past and 'fantasy imagery' as constructed from the individual's imagination, manifested as an historicfantasy continuum between the two. The emotive aspects of the definition aligned with its heritage of Dichter and motivational research in the 1950s-1960s and referred to the arousal of feelings during the consumption process such as love, hate, fear, joy, boredom, anxiety, pride, anger, disgust, sadness, sympathy, lust, ecstasy, greed, guilt, elation, shame and awe. As illustrated in the list, forms of emotional pain were also part-and-parcel of hedonic consumption (Hirschman and Holbrook, 1982; Holbrook and Hirschman, 1982).

Playfulness, construed as behaviour 'free from any immediate purpose' (Lancy, 1980: 474 cited in Holbrook and Hirschman, 1982: 138) and often evoked in shared consumption experiences (Tynan and McKechnie, 2009b), and aesthetics were highlighted as additional key characteristics of experiential consumption (Holbrook and Hirschman, 1982). Nostalgia also has its place in the experiential canon. Typically associated with older consumers recalling past lived events as evoked by specific sensory stimuli such as sounds, smells or objects (Holbrook and Schindler, 2003), nostalgia can also be encountered as vicarious nostalgia for periods typically ten to fifteen years before the birth of the consumer (Goulding, 2002).

These early papers by Hirschman and Holbrook were also important for highlighting product classes often overlooked in the mainstream marketing literature of the time. Attention was drawn to emotionally-laden, subjectively experienced products such as tourism, leisure, hospitality and entertainment. However, these facets of emotion and subjectivity are and were widely recognised in the tourism and leisure literature, as indeed is the influence on tourism research of Hirschman and Holbrook (Ritchie and Hudson, 2009). To illustrate, Seaton and Bennett (1996: 25) defined the tourism product as "partly constituted by the dreams and fantasies of its customers', Krippendorf (1987: xiv) in his compelling critique iterated people's urge 'to switch off and fill up', and The Economist (1991: 76) titled a piece 
on tourist behaviour, 'the pleasure principle' and wrote of tourists' 'unending desire for fun' securing the status of tourism as a global industry. Even the folklore of the so-called 'sun, sea, sand and sex' holiday in its various guises has at its heart the pursuit of pleasure. More recently Decrop and Snelders (2005) pointed to the importance of daydreaming, nostalgia, fantasies and feelings in vacation decision making, whilst Walls et al (2012) emphasised emotion as a central force rather than contributing influence in the tourist decision process.

Away from the consideration of specific product classes, Campbell (1987) configured the generic literature as old hedonism and new hedonism. Old, or traditional, hedonism was attached to the senses of taste, smell, touch, sight and hearing. New, or modern, hedonism was attached to the realm of emotions (including fear, pity, grief, nostalgia and reminiscing) and the possibilities for all emotions to yield pleasure when manipulated by the consumer. Thus 'the key to modern hedonism is the quest for pleasure via emotional experience rather than sensory stimulation' (Gabriel and Lang, 2006: 101), with consumers described as 'dream artists' (Campbell, 1987: 78), commodities acting as props or stimulants for the imagination, and the practice of deferred gratification forming typical characteristics of the contemporary hedonist. Recent contributions to hedonic and experiential consumption, notably by Tynan and McKechnie (2009a), have sought to inter-connect and tentatively reorientate the extant literature to the emerging re-conceptualisation of marketing under the Service-Dominant Logic (S-D Logic) of Vargo and Lusch (Baron and Harris, 2008; Tynan and McKechnie, 2009a). The emphasis placed using S-D Logic terminology on 'value-inuse' as opposed to the provider-led 'value-in-exchange' with the accompanying recognition that value creation occurs over an extended time period, the concept of 'co-creation' or the acknowledgement of the consumer as collaborator, and the appreciation of consumers as 'resource integrators' embracing physical and mental skills, energy, imagination, knowledge, competencies and social networks (Baron and Harris, 2008) are all central to S-D Logic and complementary to experiential consumption and the gift giving context.

In summary, the title ('fantasies, feelings, and fun') of the Holbrook and Hirschman (1982) iconic work guides the structure of this examination of tourism gift giving. The fantasies (imagination and dreaming), feelings (emotions), and fun (playfulness) were interrogated through the sequential stages of gift decision making, gift exchange, post-exchange, and gift consumption.

\section{Gift giving behaviour}


Gift giving behaviour with its embedded concepts and lexicon (for example donors, recipients, exchange, balanced reciprocity, donor sacrifice and so forth) has a body of research reaching back to the seminal work of Mauss (1954). Marketing academics have contributed to this knowledge base, most notably with an early model of consumer gift giving behaviour (Banks, 1979). This early model from marketing was a precursor to the renowned anthropological model of the 1980s by Sherry (1983). More recently, marketing academics have contributed to the understanding of consumer gift giving in marital relationships (Schiffman and Cohn, 2009) and to Christmas consumption rituals (McKechnie and Tynan, 2006). The absence in the canon of research of any dedicated consideration of services as gifts was partially rectified by work that specifically examined the consumer behaviour associated with tourism and leisure gifts and advanced understanding of how people decide, exchange, and consume such intangible and perishable gifts (Clarke, 2006, 2007, 2008a, $2008 \mathrm{~b}, 2009$ ). Prior to this, the topic of gift giving in tourism research was largely interpreted through the prism of souvenirs (see, for example, Nambu and Vogt, 2006; Swanson and Horridge, 2006) rather than the tourism product per se as the gift.

Although tourism and leisure as a product category lends itself to the hedonic and experiential lens, not all such products, behaviours and contexts are amenable to this approach. Closer perusal of the literature illustrated deviations from this starting point of product category. For example, Joy (2001) in her study of gift giving and social ties in Hong Kong labelled gifts (regardless of product category) as either instrumental or expressive in nature. Schiffman and Cohn (2009) isolated the existence of two opposing 'rulebooks' which govern gift giving episodes between marital partners, namely an 'economic exchange rulebook' and a 'symbolic communication rulebook'. Clearly, tourism and leisure gifts that fall into the expressive / symbolic communication rulebook are better aligned to hedonic consumption; those in the opposing camps of instrumental or economic exchange less so.

The generic literature of gift giving is thick with the symbolism of gifts as expressions of social relationships, emotional states, and 'the flow of social invisibles such as deference or affection' (Sherry, 1983: 167) between people giving and receiving gifts. Ruth (1996) highlighted five positive emotions (joy, pride, hope, gratitude, affection) which were matched to gift giving occasions where that emotion was likely to be symbolically communicated (for example, pride and graduation days, or joy and wedding ceremonies). Ruth also observed that individuals engaged in gift giving behaviour could use the process of choosing, shopping, wrapping and so forth to modify their own emotional state, and that impression management 
after gift exchange could arise from discord between felt (negative) emotion (in either party) and expressed emotion. Later work (Ruth et al, 2004) used ten emotions in the methodology - gratitude, love, pride, fear, uneasiness, embarrassment, sadness, happiness, anger, guilt and found that recipients rarely experienced single, discrete emotions but rather multiple emotions that flowed in sequence, co-existed, or exhibited both patterns.

Surprise emerged as a causative emotion that elicited further emotions and was therefore typically experienced in sequence as opposed to simultaneously with other emotions (Ruth et al, 2004). If surprise is a neutral emotion layered with a second emotion that grants positive or negative direction as argued by Vanhamme (2000), then surprise in most gift giving contexts seeks the positive. Research studies into what constitutes the 'perfect gift' identified recipient surprise as a key attribute (Belk, 1996; Durgee and Sego, 2001), with an important caveat that appreciation of gift surprise may be different in non-Western cultures. Another researched emotion in the gift giving literature was anxiety. A study of American students as gift donors (Wooten, 2000) found 13 factors contributed to the feeling of donor anxiety. These factors included collectivity (the number of people present at the exchange), formality (fears of implicit rule violation), and dissimilarity (major differences between donor and recipient on salient dimensions such as interests and values).

\section{Methodology}

Hobson's (2003) argument for more qualitative, theory-building research in tourism has resonance given the deficiency of academic research in the consumer behaviour associated with tourism and leisure as gifts. An interpretive qualitative study conducted in the United Kingdom, evidence was gathered from a stream of research with donors, recipients and industry (a.k.a. experience companies and tourism or leisure providers). The research could be synthesised as a retrospective study of actual gift giving behaviour from a cross-section of people in terms of age, gender, occupation and perspective. Consumers offered accounts of their own recent behaviour as givers and receivers of tourism gifts and the activities and responses of other parties involved. Marketing managers in industry offered accounts of their accumulated knowledge and anecdotes of the behaviour of their customers engaged in tourism gift consumption.

The stream of research was composed of four distinct phases (see Figure 1). As a flow of research methods, the telephone interviews were conducted as precursors to the main body of 
data collection. There are many experience companies offering tourism and leisure product lines packaged as gifts in the UK market. These companies include Red Letter Days, Activity Superstore, and Virgin Experience Days. Similar examples of experience companies can be found in other parts of the world, such as Smartbox in Europe, Red Balloon in Australia, and Cloud 9 Living in the USA. For this UK-based research, four Marketing Directors of leading branded experience companies participated on a de-identified basis in the preparatory phase. Their expert and specialist opinion established a context for the ensuing research, describing the patterns of tourism and leisure gift consumption at a macro-level. They also provided commentary on comparison between UK market behaviour and other developed countries, most noticeably the USA. At this juncture, it is important to reiterate that experience companies (Smartbox, Red Letter Days, Xperience Days and their ilk) are specialists in tourism and leisure gift products, but that they do not constitute the totality of tourism and leisure gifts. For the consumer, such gift opportunity is open to all providers of tourism and leisure products.

Figure 1 An Overview of the Four Phases of Research

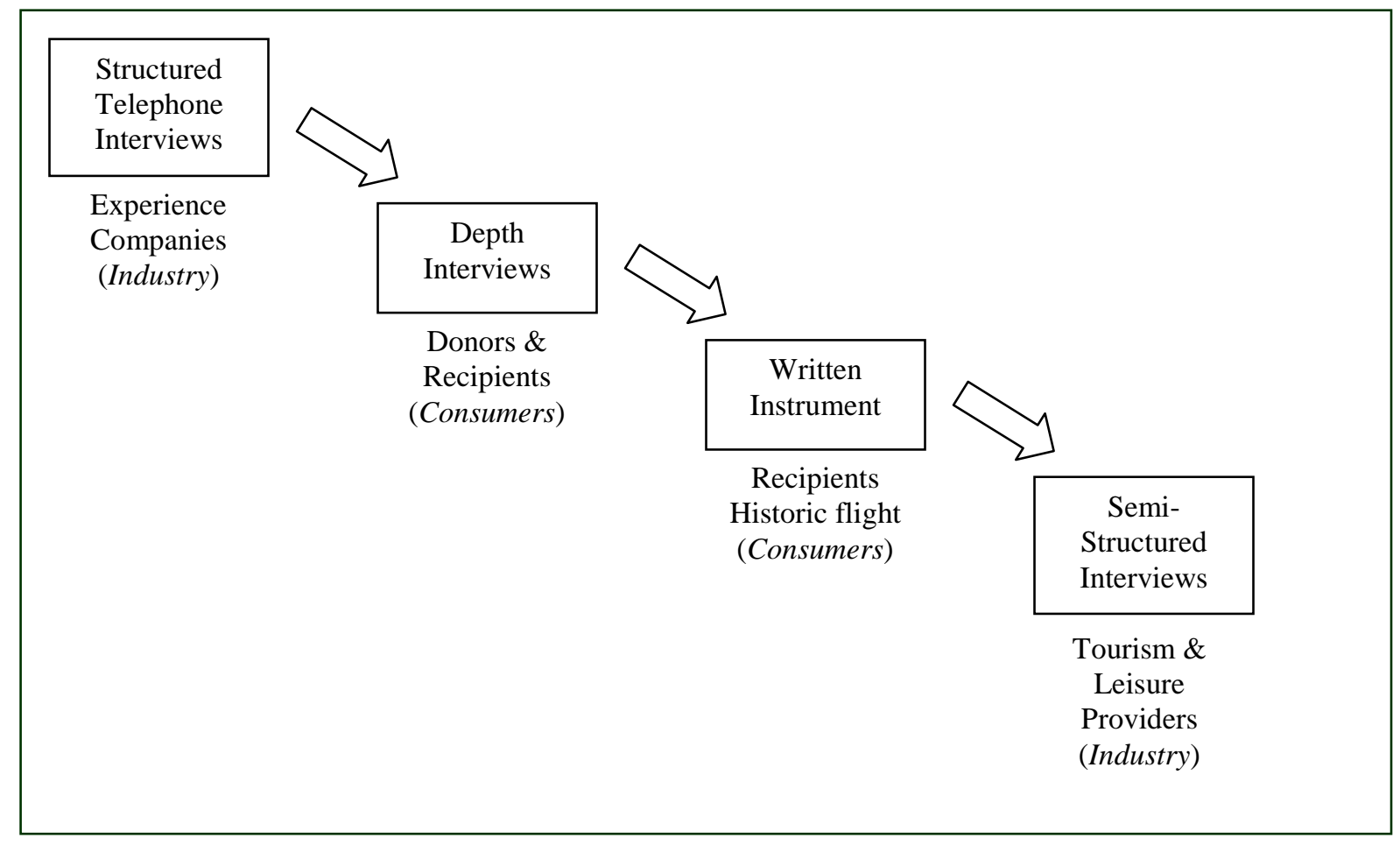

Central to the research were the depth interviews conducted with consumers who had personal experience of giving and / or receiving gifts of tourism and leisure over the 
preceding two years. A purposive sample of informants were recruited through an informantcontrolled postcard system, whereby postcards inviting participation from people meeting the two year criterion and stating researcher contact details were freely distributed through social contacts for passing on to others, allowing those interested to contact the researcher for further information in a manner convenient for them. A pro-forma sheet recording categorical data and consumer confidence in general gift giving skills was completed prior to the interview. The ten informants comprised two men and eight women between the ages of 26 and 65, and were from a range of occupations. On the pro-forma, half declared themselves as confident gift givers and half declared that they found gift giving in general to be a stressful or frustrating experience. The ten informants recounted a total of 52 tourism and leisure gift episodes. Of these episodes, 29 concerned the informant as a donor and 23 as a recipient.

The depth interviews commenced with a 'grand tour' question (as used in a gift giving study by Ruth et al, 1999) recalling a specific episode of tourism and leisure gift giving and loosely prompting the account through the stages of decision making, exchange and consumption as appropriate. Interviews were free-flowing and rich in information; as observed by one informant, "giving gifts is something that is quite nice to talk about" (Informant 7). Interviews concluded with an invitation for episodes of negative tourism and leisure gift exchanges if none had been recounted earlier. Use of this checking mechanism ensured that no contrasting or negative data was omitted. All interviews were recorded and subsequently transcribed. The data was analysed using a modified constant comparison method (Belk and Coon, 1993; Wooten, 2000), an iterative process that also checked emerging themes back against negative episodes and which absorbed data from subsequent research phases (the written instrument and industry interviews) into the analytic procedure.

The third phase of the research involved access to recipients of an historic flight gift negotiated through the active participation of a flight experience company focusing on Tiger Moths and Hurricane airplanes. A self-completion written instrument was administered by the company's ground crew at four United Kingdom airfields (South Yorkshire, Manchester, Leicestershire, and Surrey). Clients who had been given their historic flight as gifts were invited by staff to complete the structured instrument at the airfield in the immediate aftermath of taking their flight. A total of 137 usable instruments were returned (117 male, 20 female; age range 18 to over 65; mix of occupations and retired).

The final phase consisted of semi-structured interviews with practitioners responsible for marketing in four tourism and leisure providers. Access was negotiated on a de-identified basis through existing researcher contacts and cold-calling. Variety was sought between the 
providers in terms of tourism and leisure sub-sector and size; three were locally-based and one at some distance. These providers varied in their level of marketing activity regarding their products as gifts. The key criterion for participation in the study was the recognition that, with or without targeted marketing effort, consumers were purchasing and using the provider's products as gifts to maintain and nurture their personal relationships. This recognition of consumer behaviour stimulated their interest in the study. The four providers participating in the research were

- Provider A: a small river cruise operator using Edwardian-style river launches and offering scheduled trips and private charters in the Oxford area

- Provider B: a leading entrance fee-based heritage attraction with approximately 400,000 visitors a year

- Provider C: a small, specialist tour operator taking under 500 tourists a year to a single, Middle Eastern country

- Provider D: a mid-sized tour operator focusing on the 50 years old plus market; a household brand name with a broad product portfolio and taking approximately 200,000 tourists a year to destinations across the globe.

The interview process with these disparate providers highlighted something of the below-thewaterline consumer gift giving activity. Hard fact from marketing information systems was not available and the informant took time in exploring, pondering and discussing their thoughts and illustrations. The interview was appreciated as an opportunity to crystallise viewpoints and direction, with one provider commenting that "It's nice to talk to you about it because whenever you talk to people about it, it helps to clarify it in your own mind a bit" (Provider A).

\section{Methodological limitations}

The interface between experiential aspects of tourism gift consumption as the subject of study and the research methods used gives rise to two limitations that are reflected upon here. Firstly, the problem of informant recall of specific episodes as the majority of informants were in the post-consumption stage of the gift recounted. The methodology and informant selection procedure was not designed to capture informants in identifiable consumption 
stages. Of less concern for the more factual aspects of tourism gift giving, for something as invisible, dynamic and expressive as feelings, fantasies and fun, such time lags could distort and remould original impressions. Partial redress was found in interview informants who were at earlier stages, in particular, the planning and decision making stage, and also in the historic flight recipients who were at the precise stage of the immediate aftermath of use. Secondly, as noted by Holbrook and Hirschman (1982), a verbal and written methodology may be limited by informant abilities to articulate information - for example, feelings and emotions - and may not be finely enough tuned for capturing non-verbal forms of sensory information such as pictorial images, tastes, or smells.

\section{Findings and discussion}

The consumer behaviour of the givers and receivers of tourism and leisure gifts has been configured in a model of experience gift consumption, which offers a plausible and evidencebased account from decision making through to post-consumption (Clarke, 2008a, 2008b). Figure 2 presents a synthesis of this work, expressly to set out a skeletal structure on which to hang experiential consumption - the findings for Hirschman and Holbrook's (1982) fantasies (imagination and dreaming), feelings (emotions) and fun (playfulness). Feeding into the flow diagram on the right are three types of tourism and leisure gifts as selected by donors (Clarke, 2009) - the straight purchase (bought from a single provider), the modified purchase (additions by the donor such as drinks or a meal bolted onto the product), and the created gift (arguably 'home-made' gifts crafted by donors amalgamating different components from combinations of providers). These tourism and leisure gifts can also be designed by the person giving the gift for immediate one-off consumption at the moment of exchange, for delayed consumption after exchange (allowing for recipient involvement in planning final arrangements and heightened anticipation), and for serial consumption across a number of dates (for example, National Trust membership or golfing lessons). These three usage-related behaviours which impacted on experiential consumption are also highlighted in Figure 2. Both delayed and serial consumption could be associated with the practice of deferred gratification as noted by Gabriel and Lang (2006).

The findings for fantasies, feelings and fun are presented, drawing upon both giver and receiver experience from the various perspectives of the research informants. It should be 
noted, however, that these three categories (fantasies, feelings and fun) are not discrete but impact on each other; Hirschman and Holbrook's (1982) mutual evocation.

Figure 2. A Synthesis of the Tourism and Leisure Gift Consumption Process

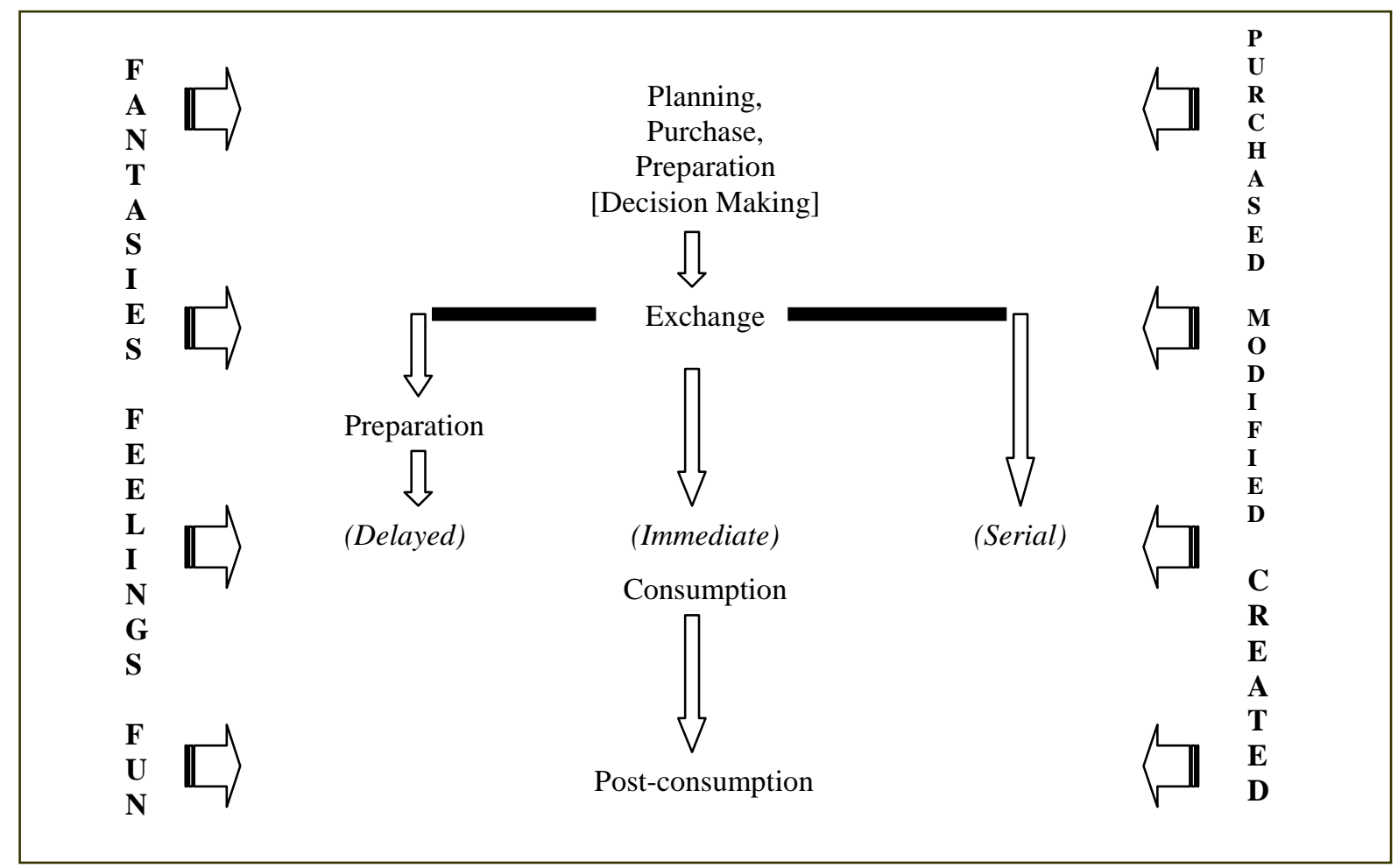

\section{Fantasies}

The wrapping of gifts is a common element of ritual in gifting behaviour (Hendry, 1993), and one that needs some re-thinking by donors in the context of intangible gifts. Simple cards and envelopes were used to wrap the voucher, ticket or written promise, but donors also made use of large boxes to waylay any notion of a tourism or leisure gift and to stimulate the recipient's imagination into the realms of physical goods;

"If you've got something like a box in front of you, you are, well, 'what's that?' and you wouldn't automatically think 'Oh that's a ...', unless it's an envelope, you wouldn't think about a voucher for something. I think because he got something in a box, he's probably thinking 'Now that's probably too big for a computer game, I wonder what it could be?'” (Informant 9). 
Donors teased the intended recipients of their gifts ahead of gift exchange thus stimulating their imaginations into anticipating unexpected gifts; "making quite fanciful suggestions" (Informant 4). A more elaborate fantasy-inducing mechanism was also employed by donors, that of the decoy strategy. Recipients were issued in advance of gift exchange with written or verbal lists of things they needed to do or take, with a handful of the items being correct and the others deliberately included to mislead (thus maintaining the surprise) and to stimulate extravagant fantasies. For example, instead of correctly anticipating kayaking on the Welsh borders, one recipient (having dreamed of “about four different scenarios") conjured up fantasies of "bog snorkelling in Wales" in response to a donor's decoy strategy of creating a list of "the most ridiculous things that I could bring" (Informant 8). According to Palmer (2010), anticipation of an activity or event is of itself an experiential benefit serving to crank up recipient fantasy and excitement.

For gifts designed for immediate consumption, donors had the option of using a follow me strategy over a short time period. This mechanism was rooted in suspense and triggered the imagination of the recipient in rapid succession. The recipient was instructed to be "ready" at a particular time and place, and the three components - the activity, the destination, the participants (the what, where and who) - were successively revealed to the receiver of the gift. Such a strategy prompted an alert or mindful state (Langer, 1989) in the recipient, who actively searched for "clues" in the clothing of the donor, in accompanying items, and in journey directions. In one episode, unaware of any of the three components at 9am on Friday, the recipient of a boat trip on the River Thames first knew that her sister-in-law and motherin-law were participants (who) when they arrived at the house; "and I still didn't know where we were going [where] and we had a picnic hamper, but I couldn't quite work out what it was until they got to the boat yard around Jericho [what]" (Informant 5. Researcher's brackets). In a different episode (a trip to EuroDisney), another recipient also experienced the follow me strategy and emphasised the journey in his account;

"I suspected because we were only going for a long weekend that it would be France
[where] and not much further...I suspected it was Disney [what] and we started
heading towards Paris. I was $99 \%$ sure it was Disney before we got there" (Informant 2. Researcher's brackets)

It is interesting to note the possible quality of imaginative engagement under the follow me strategy which appeared to be more orientated to working out the puzzle, finding the solution, 
and its practical ramifications than under the decoy strategy with its longer timeframe and its directive to day-dream.

Supplementary and tangible gifts were used as Campbell's (1987) props or stimulants for the imagination too, but more often in a support role. Pilot teddy bears dressed in goggles, flying jacket and scarf were a popular choice for the historic flight gift; a fur hat in support of a winter New York trip; a CD of a much-admired jazz singer in anticipation of a London trip incorporating a live performance by this artist. Such supplementary gifts served to bridge any temporal gap between exchange and consumption, helping the recipient's imagination to focus on the anticipated experience by providing a visual, tactile and even acoustic prompt. The range of supporting gifts as stimulants could be extended from this dataset to include olfactory props such as perfumes with particular associations for the recipient. The point is that these additional gifts can hold multisensory appeal and be used by recipients to trigger fantasies and imagination at both pre-consumption (anticipatory) and post-consumption (memory) stages.

The emphasis was towards the fantasy imagery of Hirschman and Holbrook (1982) but there was evidence of historic imagery too. For example, a London trip "was really cool 'cos we grew up in London" (Informant 8), whilst an historic flight respondent was "very pleased to fly a Moth again after some 50 years" (Respondent 26 - historic flight) and another expressed "pleasure to fly in an aircraft I first flew in 61 years ago" (Respondent 36 historic flight). A blend of fantasy and historic imagery along a continuum was typically a more natural fit than a tight categorisation into one or other option. For example, an episode of a half-day tank driving referenced back to 'the boy that used to play army games in the garden ... harking back to his childhood' (Informant 9), illustrating a blend between fantasy imagery (imagining driving tanks) and historic imagery (playing garden war games as a small boy).

\section{Feelings}

Tourism and leisure gifts were emotion-laden. Those giving and receiving gifts displayed a range of emotions throughout the stages of the consumption process, and both positive and negative emotions were exhibited. Excitement (for example, "a really exciting experience" Respondent 135 - historic flight) and exhilaration (for example, “a wonderful exhilarating experience, not to be missed" Respondent 84 - historic flight) featured as emotions for recipients of historic flights, both emotions with strong sensory inputs. Other positive 
emotions expressed by recipients upon gift exchange or consumption included liking, love, enjoyment, delight, thrill, wonder, and pleasure (occasionally more imaginatively described, for example, "tickled pink" Informant 7 or "chuffed to bits" Informant 9). Perhaps the strongest pronouncement of pleasure was the statement "second only after the birth of my daughters" (Respondent 30 - historic flight). Of course, the arousal of positive emotions in the recipient is a fundamental principal of gift giving for most exchanges. Less predictable were the positive emotions encountered by donors in decision making, anticipation and gift exchange. One donor was described as having "bounced in very pleased with himself" (Informant 7) upon identifying and purchasing a tourism gift, another asserted "huge enjoyment from sorting it out" (Informant 4), whilst a white water rafting trip was identified as "the big one, the thing he was excited about giving" (Informant 10). The anticipation of the surprise at gift exchange was at times strong enough for donors to believe that their emotions were greater than those of the person receiving the gift; "I was so excited. I think I might have been more excited than him actually" (Informant 8).

Conversely, negative emotions were also evident. Disappointment, embarrassment, shame, guilt, boredom and (mental) pain were all expressed, alongside anxiety and worry. To illustrate, disappointment for a recipient with one part of the gift that did not come to fruition, boredom for a donor during consumption who disliked visiting heritage attractions but did so because the recipient enjoyed this, and embarrassment for one donor in a group less able to contribute financially to the gift, a hot air balloon trip ("shamed her a little bit, well, not shamed, embarrassed her" Informant 6). The research focus was on the donor and recipient but some commentary was offered on the emotions of third parties. For example, the perceived envy of onlookers at gift exchange, denoting the desirability of the tourism or leisure gift.

Surprise was the initial emotion that the decoy strategy and follow me strategy were planned to elicit. Informants expressed the strength of surprise with various vocabulary; for example, "a complete surprise" (London experience package), "a mouth drop" (Formula One rally driving), "total surprise” (Flying lesson), "they were both stunned” (Le Manoir trip), "he was really shocked and surprised" (Football season ticket). One informant reconnected surprise to donor feelings of pleasure, succinctly stating that "it's part of the pleasure of giving gifts - the surprise" (Informant 7). A cautionary note from the impact of negative surprises urged an eye to the practicalities and argued for " $a$ surprise that's workable” (Informant 10). 
Nostalgia and reminiscing were notable emotions for tourism and leisure gifts and these emotions interface with the use of historic and fantasy imagery. The historic flights that were purchased as gifts for the elderly men who had flown Tiger Moths and Hurricanes in their youth appeared illustrative of Holbrook and Schindler's (2003) emotionally-charged nostalgic bonding (with the type of airplane) at the critical age of young adulthood (twenties).

On the negative side, anxiety and worry were also recounted emotions for tourism and leisure gifts. As for other gift categories, donors of tourism and leisure gifts expressed anxiety ahead of gift exchange, but more interestingly, and in-tune with the perishable and inseparable characteristics of the product, during consumption also. For example, traffic congestion and road works during travel to the location stimulated anxiety in the donor;

'I hope we're going to be there', and I was a little bit anxious, I must admit, and I was thinking 'oh gosh, I don't want to get there late and me ruin it for him'. You know, it gets ruined for him. So I was a little bit anxious about that'” (Informant 9).

Some of these gifts resulted in anxiety for recipients, either through perceived physical risk ("quite nervous" for a flying lesson Informant 4) or perceived social risk ("What? Am I supposed to go on my own or something?" I'd probably feel a little bit anxious, oh, anxious" Informant 9). This recipient anxiety caused by anticipated isolation in a social group relates also with the experiential aspects of sharing the consumption experience discussed in the next section.

\section{Fun}

Fun and playfulness were evident throughout the consumption process, and, as might be expected, prevalent in the consumption stage itself. Donors and recipients made references to "joking about" (Informant 1) during the usage of the gift. Successful donors needed to plan ahead for the recipient's pleasure in consuming the gift by anticipating the nature of the likely co-consumers.

Four consumption or sharing patterns were identified, these being donor as participant, donor as spectator, significant other(s), and co-consumers (Clarke, 2007). The first two, namely donor as participant and donor as spectator, draw some comparison to Pine and Gilmore's (1998) active and passive customer participation. Donor as participant required the tourism gift giver to be fully immersed in the activity, taking part alongside the recipient. 
This form of sharing was of lowest risk to the recipient, allowed the donor to assert a measure of control over the experience, and encouraged a deeper bonding in the relationship. It was not always the chosen option as financial constraints, differing lifestages, geographical distance or health issues intervened. It was a form of sharing amenable to playfulness; "he got part of the fun as well" (Informant 1). Donor as spectator required the donor to accompany the recipient but electing to watch the central activity. Of the historic flight gifts, $77 \%$ involved the donor as spectator. Such donors might still participate in other components of the total gift, for example, drinks afterwards or a meal. This form of sharing allowed for the expression of feelings and recounting of the experience, pumping up the vicarious sense of fun, whilst again granting donors some control over the experience. Significant other(s) required the recipient to share the gift with people close to them, other than the donor, such as friends or family. It was often chosen where geographical separation between donor and recipient, differing lifestyles or lifestages were apparent - for example, go-karting with teenage friends rather than the adult donor. Finally, sharing in the form of co-consumers required the recipient to attend alone and to bond with strangers undertaking the activity concurrently. It was arguably the riskiest form of sharing, with the success or otherwise of the gift made or marred by the inter-compatibility of these co-users in the absence of the donor. For the gift of a half-day of rally driving, "quite a big camaraderie" between the car drivers was created by "the banter that was going on" and "chivvying each other along" (Informant 9). However, reliance on experience co-users was also considered by recipients to be potentially anxiety-inducing, not an emotion best in-tune with a sense of playfulness. As one informant described the position, “you don't fancy going white water rafting by yourself in the Lake District do you? Who do you know who is going to be really thrilled?" (Informant 10).

A sense of playfulness and fun was also brought into other stages of the consumption process. For example, donors sometimes used playful or jokey surrogates to represent the tourism and leisure gift at the point of exchange. Cartoon football socks, "silly socks for Christmas" (Informant 10), were wrapped around a football season ticket. Another informant referenced themselves and the recipient as "complete kiddies" (Informant 9) at gift exchange, a form of playfulness echoing childhood behaviour. Both the follow me strategy and the decoy strategy were steeped in playfulness with strong overtones of surprise. Even the decision making stage demonstrated playfulness where groups of donors were involved; a home-made or created gift of a London experience helped bring a group of family donors together and "I'd say that the planning of the birthday weekend is giving the people 
organising it a lot of fun and enjoyment, just talking about it and planning it and anticipating what his reactions are going to be” (Informant 4).

\section{Conclusion and Managerial Implications}

The purpose of this paper was to examine the behaviour of consumers in the decision making, exchange, and consumption of gifts that are tourism and leisure products, with a particular focus on their experiences of feelings, fantasy and fun (Holbrook and Hirschman, 1982) throughout the consumption process. Tourism and leisure as gifts are rich in emotions and feelings, conducive for dreaming and fantasies, and replete with opportunities for playfulness and surprise. Donors through their gifting practice have invented mechanisms (such as the follow me strategy, the decoy strategy, donor as participant etc) for enhancing these experiential aspects of consumption, including the possibilities for delayed gratification through gifts involving delayed or serial consumption. There is a gap between real-world consumer behaviour that makes use of tourism and leisure products as gifts and the academic literature. Arguably there is also a gap between real-world consumer behaviour and industry understanding as, outside of the commercial experience companies and some enlightened tourism and providers, little is done to capture donor and recipient data and still less to target this market.

This paper concludes by proposing seven areas for tourism and leisure marketers to address for success in the gift giving market. These focal areas move from more general issues connected to tourism and leisure as gifts to the more experientially specific.

The first is that tourism and leisure marketers should identify and then leverage networks and partnerships with other tourism and leisure providers in the vicinity to provide opportunities for consumers (as donors) to create hand-made gifts or make modifications to a core product from complementary components. For example, an activity provider (eg white water rafting) should recommend eateries, accommodation options and so forth that complement in some way the nature of the gift. As indicated in the second focal area below, not all potential gift buyers will be familiar with the locality and yet are planning to surprise the recipient (who in other circumstances might be the natural person to advise). Under these circumstances recommendations from the provider can be particularly appreciated. Prearranged discounts or value-added promotions within the networks and partnerships can enhance the attractiveness of the gift offer. 
The second is that tourism and leisure marketers should assess the potential advantages and disadvantages of the tourism gift giving market in respect of the individual organisation. Possible advantages, the merits of which need to be taken into careful consideration, include the potential generation of cash flow and advanced sales in trough usage periods. For example, white water rafting in the UK has a trough period in terms of usage in November, December and January, but could benefit greatly from the Christmas gift giving season in terms of advanced sales. Another possible advantage is the opening up of non-traditional and non-geographically restricted buyer segments as donors buy for others better suited to the product. White water rafting may be used by younger people but as a gift can be bought by all age and lifestyle groups including those who would never raft themselves. Likewise, the gift can be bought by someone anywhere in the world through digital technology whereas the actual user has to travel to, or reside in, the rafting location. A third possible advantage is the generation of additional revenue from the initial booking as tourism gift recipients often bring significant others with them to share the experience. Thus a gift of one white water rafting trip may lead to a group booking of three, four or five rafting companions, additional revenue stimulated by the efforts of the customer in persuading others to join, rather than from the direct marketing expenditure of the tourism provider.

The third area revolves around how best to adapt existing or develop new cost-effective marketing information systems to capture data about the purchasing and usage activity of tourism and leisure products as gifts. As stated earlier, gift giving is a market largely overlooked by tourism and leisure providers (though not by the commercial experience companies) and much of the understanding gleaned by marketers is anecdotal and cumulative from customer contact. For effective decision making, systematic data collection is required to ensure that both donors and recipients are appropriately identified and profiled and subsequent targeting decisions fine-tuned accordingly. The fourth area of attention flows from the establishment of such systems as the pre-use information requirements and the inuse needs, benefits sought and behaviours displayed for distinct buyer (donor) and user (recipient) groups are understood and acted upon by tourism and leisure providers.

The fifth requires the tourism and leisure marketer to assess how well the different forms of sharing in consumption (donor as participant, donor as spectator, significant other(s), coconsumers) are recognised and subsequently planned for and integrated into the product design. The marketer needs to consider what processes are in place to maximise the opportunities for donors as spectators to join in the fun, contribute to the playfulness, and immerse in the emotions. Conversely, the marketer also needs to consider how to mitigate 
any tendency towards anxiety that the recipients who are reliant on co-consumers rather than significant others might demonstrate.

The sixth is a recommendation to tourism and leisure providers deciding to target the gift buying public to conduct a multisensory audit or blueprint of the product offer. The audit or blueprint should analyse the consumer experience from initial entry and welcome through to exit and departure. Remote touchpoints important in the decision making process should also be taken into account. For example, the incorporation of the river-in-spate sounds of white water rafting into the requisite website may communicate the attractiveness of the potential gift at a key decision stage. Such a multisensory audit exercise could be expected to highlight innovative opportunities to embed the multisensory aspects of the consumer experience (tastes, sounds, scents, tactile impressions and visual imagery) into the existing product design.

The final and seventh area focuses on the physical goods (with due attention to the attendant multisensory properties) that could best be used as props (Campbell, 1987) for the imagination of consumers. Such props needs to represent the intangible tourism and leisure gift during the rituals of gift exchange and to stimulate dreams and fantasies in the likely time lag between gift exchange and gift consumption (and even onwards into memory).

As shown by the success of the commercial experience companies (Red Letter Days, Smartbox, Cloud 9 Living and their ilk), consumers are using intangible tourism and leisure products as gifts for others in sufficient numbers to drive business models. Tourism and leisure providers need to assess the potential of this market for their own circumstances, to recognise the experiential perspective as demonstrated in this paper, and to adapt their marketing activities accordingly. 


\section{References}

Banks SK (1979) Gift-giving: a review and interactive paradigm. Advances in Consumer Research 6(1): 319-324.

Baron S and Harris K (2008) Consumers as resource integrators. Journal of Marketing Management 24(1-2): 113-130.

Belk, R.W. (1996) The perfect gift. In: Otnes, C. and Beltramini, RF (eds) Gift Giving. A Research Anthology. Bowling Green OH USA: Bowling Green State University Popular Press, 59-84.

Belk RW and Coon GS (1993) Gift giving as agapic love: an alternative to the exchange paradigm based on dating experiences. Journal of Consumer Research 20(3): 393-417.

Campbell C (1987) The Romantic Ethic and the Spirit of Modern Consumerism. Oxford UK: Basil Blackwell.

Caru A and Cova B (2003) Revisiting consumption experience: a more humble but complete view of the concept. Marketing Theory, 3(2): 267-392.

Clarke, J. (2006) Different to 'dust collectors'? The giving and receiving of experience gifts. Journal of Consumer Behaviour, 5(6): 533-549.

Clarke, J. (2007) The Four 'S's' of experience gift giving behaviour. International Journal of Hospitality Management, 26(1): 98-116.

Clarke, J. (2008a) Gifts of tourism: insights to consumer behaviour. Annals of Tourism Research, 35(2): 529-550.

Clarke, J. (2008b) Experiences as gifts: from process to model. European Journal of Marketing, 42(3-4): 365-389.

Clarke, J. (2009) Purchased, modified, created: consumer voices in experience gifts. Service Industries Journal, 29(9): 1-14.

Decrop A and Snelders D (2005) A grounded typology of vacation decision-making. Tourism Management 26(2): 121-132.

Durgee JF and Sego T (2001) Gift giving as a metaphor for understanding new products that delight. Advances in Consumer Research 28(1): 64-69.

Gabriel Y and Lang T (2006) The Unmanageable Consumer. London: Sage Publications.

Goulding C (2002) An exploratory study of age related vicarious nostalgia and aesthetic consumption. Advances in Consumer Research 29(1): 542-546. 
Hendry J (1993) Wrapping Culture. Politeness, Presentation and Power in Japan and Other Societies. Oxford UK: Clarendon Press.

Hirschman EC and Holbrook MB (1982) Hedonic consumption: emerging concepts, methods and propositions. Journal of Marketing 46 (Summer): 92-101.

Hobson PJS (2003) The case for more exploratory and grounded tourism research. The Martin Oppermann Memorial Lecture, 2001. Pacific Tourism Review 6 (2): 73-81.

Holbrook MB (2000) The Millennial consumer in the text of our times: experience and entertainment. Journal of Macromarketing 20(2): 178-192.

Holbrook MB and Hirschman EC (1982) The experiential aspects of consumption: consumer fantasies, feelings and fun. Journal of Consumer Research 9(2): 132-140.

Holbrook MB and Schindler RM (2003) Nostalgic bonding: exploring the role of nostalgia in the consumption experience. Journal of Consumer Behaviour 3(2): 107-127.

Joy A (2001) Gift giving in Hong Kong and the continuum of social ties. Journal of Consumer Research 28(2): 239-256.

Krippendorf J (1987) The Holiday Makers. Understanding the Impact of Leisure and Travel. Oxford UK: Heinemann.

Langer EJ (1989) Minding matters. The consequences of mindlessness-mindfulness. Advances in Experimental Social Psychology 22: 137-173.

Mauss M (1954) The Gift. Forms and Functions of Exchange in Archaic Societies. London: Cohen and West.

McKechnie S and Tynan C (2006) Social meanings in Christmas consumption: an exploratory study of UK celebrants' consumption rituals. Journal of Consumer Behaviour 5(2): $130-144$.

Nambu T and Vogt CA (2006) Investigating Japanese travelers' motives and gift buying on leisure travel to the United States. Tourism Review International 9(3): 247-259.

Palmer A (2010) Customer experience management: a critical review of an emerging idea. Journal of Services Marketing 24(3): 196-208.

Pine BJ and Gilmore JH (1998) Welcome to the experience economy. Harvard Business Review, July-August: 97-105.

Ritchie JRB and Hudson S (2009) Understanding and meeting the challenges of consumer / tourist experience research. International Journal of Tourism Research 11(2):111-126.

Ruth JA (1996) It's the feeling that counts: toward an understanding of emotion and its influence on gift-exchange processes. In: Otnes $\mathrm{C}$ and Beltramin R (eds) Gift Giving. A 
Research Anthology. Bowling Green OH USA: Bowling Green State University Popular Press, 195-213.

Parsons E and Maclaran P (2009) Contemporary Issues in Marketing and Consumer Behaviour. London: Routledge.

Ruth JA, Otnes CC and Brunel FF (1999) Gift receipt and the reformulation of interpersonal relationships. Journal of Consumer Research 25(4): 385-402.

Ruth JA, Brunel FF and CC Otnes (2004) An investigation of the power of emotions in relationship realignment: the gift recipient's perspective. Psychology \& Marketing 21 (1): 29-52.

Schiffman LG and Cohn DY (2009) Are they playing by the same rules? A consumer gifting classification of marital dyads. Journal of Business Research 62(11): 1054-1062.

Seaton AV and Bennett MM (1996) Marketing Tourism Products. Concepts, Issues, Cases. London: International Thomson Business Press.

Sherry JF (1983) Gift giving in anthropological perspective. Journal of Consumer Research 10(2):157-168.

Swanson KK and Horridge PE (2006) Travel motivations as souvenir purchase indicators. Tourism Management 27(4): 671-683.

The Economist (1991) Travel and tourism. The pleasure principle. The Economist 318 (7699): 76-78.

Tynan C and McKechnie S (2009a) Experience marketing; a review and reassessment. Journal of Marketing Management 25(5-6): 501-517.

Tynan C and McKechnie S (2009b) Hedonic meaning creation through Christmas consumption: a review and model. Journal of Consumer Behaviour 8(3): 237-255.

Vanhamme J. (2000) The link between surprise and satisfaction: an exploratory research on how best to measure surprise. Journal of Marketing Management 16(6): 565-582.

Vargo SL and Lusch RF (2004) Evolving to a new dominant logic for marketing. Journal of Marketing 68(1): 1-17.

Walls AR, Okumus F and Wang Y (2012) Cognition and affect interplay: a framework for the tourist vacation decision-making process. Journal of Travel \& Tourism Marketing 28(5): 567-582.

Wooten DB (2000) Qualitative steps toward an expanded model of anxiety in gift giving. Journal of Consumer Research 27(1): 84-95 